\title{
Malignant pleural mesothelioma
}

Walter Klepetko

Published online: 25 July 2016

(C) Springer-Verlag Wien 2016

Dear Reader,

Malignant pleural mesothelioma (MPM) is a rare but highly malignant disease. Although it is not officially accepted as an orphan disease, its low incidence imposes significant difficulties to physicians confronted with affected patients.

To date, no uniform curative treatment strategy has been identified and the search for better treatment options remains an important challenge.

In view of this background, a group of Austrian physicians assembled several years ago with the intention of forming the so-called Austrian Mesothelioma Interest Group (AMIG). The goal of this group was to

W. Klepetko on behalf of the members of the Austrian Mesothelioma Interest Group (AMIG).

Univ. Prof. Dr. W. Klepetko $(\varangle)$

Division of Thoracic Surgery, Department of Surgery,

Comprehensive Cancer Center, Medical University Vienna,

Vienna, Austria

thoracicsurgery@meduniwien.ac.at collect data on patients with MPM in Austria, with the perspective of better describing the incidence, treatment mode, and outcome of this disease. With very few exceptions, all larger pulmonology departments and many other smaller units in Austria have contributed to this project. Regular meetings were held by the group over the years, which aimed to review the available data, to intensify the dialogue, to increase knowledge about recent developments, and to raise awareness in general.

In the following trilogy of publications, the most important aspects of MPM are summarized. Part 1 describes the epidemiology, diagnosis, and staging. Part 2 overviews the therapeutic approaches currently available. Finally, Part 3 represents a summary of the data that have been collected by the AMIG during the last few years.

With this series of papers, the AMIG members hope to contribute to the improvement of the situation of MPM patients in Austria.

Conflict of interest W. Klepetko declares that he has no competing interests. 


\begin{tabular}{|c|c|}
\hline \multicolumn{2}{|c|}{ Members of the AMIG are (alphabetical order) } \\
\hline Ambrosch G. & Department of Pulmonology, Landeskrankenhaus Graz West, Graz, Austria \\
\hline Arns M. & Department of Pulmonology, Landeskrankenhaus Hochegg, Hochegg, Austria \\
\hline Augustin $\mathrm{F}$. & Department of Surgery, University Clinic Innsbruck, Innsbruck, Austria \\
\hline Baumer $\mathrm{H}$. & Department of Cardio-Thoracic Surgery, Klinikum Klagenfurt, Klagenfurt, Austria \\
\hline Baumgartner B. & Department of Pulmonology, Landeskrankenhaus Vöcklabruck, Vöcklabruck, Austria \\
\hline Bitterlich E. & Department of Pulmonology, Landeskrankenhaus Vöcklabruck, Vöcklabruck, Austria \\
\hline Blazek G. & Department of Pulmonology, Krankenhaus Hietzing, Vienna, Austria \\
\hline Bolitschek J. & Department of Pulmonology, Hospital of Elisabethinen Linz, Linz, Austria \\
\hline Cerkl P. & Department of Pulmonology, Landeskrankenhaus Hohenems, Austria \\
\hline Dong $Y$. & Division of Thoracic Surgery, Medical University of Vienna, Vienna, Austria \\
\hline Eckmayr J. & Department of Pulmonology, Landeskrankenhaus Wels, Wels, Austria \\
\hline Errhalt P. & Department of Pulmonology, University Clinic Krems, Krems, Austria \\
\hline Flicker M. & Department of Pulmonology, Landeskrankenhaus Leoben, Leoben, Austria \\
\hline Geltner C. & Department of Pulmonology, Klinikum Klagenfurt, Klagenfurt, Austria \\
\hline Handzhiev S. & Department of Pulmonology, University Clinic Krems, Krems, Austria \\
\hline Hasenhüttl N. & Department of Pulmonology, Landeskrankenhaus Hörgas-Enzenbach, Enzenbach, Austria \\
\hline Hernler T. & Department of Pulmonology, Landeskrankenhaus Hohenems, Austria \\
\hline Hoda M.A. & Division of Thoracic Surgery, Medical University of Vienna, Vienna, Austria \\
\hline Jamnig $\mathrm{H}$. & Department of Pulmonology, Landeskrankenhaus Hochzirl-Natters, Natters, Austria \\
\hline Kirchbacher K. & Department of Pulmonology, Wilhelminenspital, Vienna, Austria \\
\hline Klepetko W. & Division of Thoracic Surgery, Medical University of Vienna, Vienna, Austria \\
\hline Klikovits T. & Division of Thoracic Surgery, Medical University of Vienna, Vienna, Austria \\
\hline Kneussl M & Department of Pulmonology, Wilhelminenspital, Vienna, Austria \\
\hline Machan B. & AUVA Rehabilitation Clinic Tobelbad, Tobelbad, Austria \\
\hline Olschewski H. & Division of Pulmonology, Department of Internal Medicine, University Clinic Graz, Graz, Austria \\
\hline Pohl W. & Department of Pulmonology, Krankenhaus Hietzing, Vienna, Austria \\
\hline Polachova J. & Division of Pulmonology, Department of Internal Medicine, University Clinic Graz, Graz, Austria \\
\hline Popper H. & Department of Pathology, Medical University Graz, Graz, Austria \\
\hline Porsch P. & Department of Pulmonology, University Clinic Salzburg, Salzburg, Austria \\
\hline Schenk P. & Department of Pulmonology, Landeskrankenhaus Hochegg, Hochegg, Austria \\
\hline Schmid T. & Department of Surgery, University Clinic Innsbruck, Innsbruck, Austria \\
\hline Speiser M. & Department of Pulmonology, University Clinic Krems, Krems, Austria \\
\hline Stockhammer P. & Division of Thoracic Surgery, Medical University of Vienna, Vienna, Austria \\
\hline Studnicka M. & Department of Pulmonology, University Clinic Salzburg, Salzburg, Austria \\
\hline Trockenbacher $\mathrm{C}$. & Department of Pulmonology, Landeskrankenhaus Wels, Wels, Austria \\
\hline Wandschneider W. & Department of Cardiothoracic Surgery, Klinikum Klagenfurt, Klagenfurt, Austria \\
\hline Wonisch S. & AUVA Rehabilitation Clinic Tobelbad, Tobelbad, Austria \\
\hline Wurm R. & Division of Pulmonology, Department of Internal Medicine, University Clinic Graz, Graz, Austria \\
\hline Zöchbauer-Müller S. & Division of Oncology, Department of Medicine I, Medical University of Vienna, Vienna, Austria \\
\hline
\end{tabular}

